\title{
Viral bronchiolitis for the clinician
}

\author{
Dominic A Fitzgerald \\ Department of Respiratory Medicine, The Children's Hospital at Westmead, Westmead, New South Wales, Australia
}

\begin{abstract}
Viral bronchiolitis is common, and about $98-99 \%$ of infants are managed in the home. Because about $95 \%$ of infants $<2$ years old are infected with respiratory syncytial virus, however, bronchiolitis is the commonest reason for admission to hospital in the first 6 months of life. It is usually a self-limiting condition lasting around a week in previously well children. About $1 \%$ of infants are admitted to hospital, and about $10 \%$ of hospitalised infants will require admission to the intensive care unit. Respiratory syncytial virus is isolated from about $70 \%$ of infants hospitalised with bronchiolitis. The emphasis of hospital treatment is to ensure adequate hydration and oxygenation. Other than supplemental oxygen, little in the way of pharmacological treatment has been demonstrated to alter the course of the illness or the risk of wheezing in the months following bronchiolitis.
\end{abstract}

Key words: bronchiolitis; evidence-based management; non-invasive respiratory support; pharmacological treatment; respiratory syncytial virus (RSV); wheezing outcomes.

\section{Introduction}

Bronchiolitis is the commonest reason for admission to hospital in the first 6 months of life. ${ }^{1,2}$ It describes a clinical syndrome of cough, tachypnoea, feeding difficulties and inspiratory crackles on chest auscultation. Wheezing may be associated but is not an essential feature of the illness. The upper age for bronchiolitis is limited to 12 months of age in the majority of the Australasian and English reports. However, European and North American publications often consider the diagnosis up to the age of 3 years and often define bronchiolitis as a wheezing illness, which leads to difficulties in comparing international studies. While many viruses may give rise to the clinical syndrome of bronchiolitis, respiratory syncytial virus RSV is most frequently implicated in hospitalised cohorts of infants. ${ }^{1-3}$ Treatment is predominantly symptomatic, with an emphasis on maintaining adequate hydration and providing supplemental oxygen in moderate to

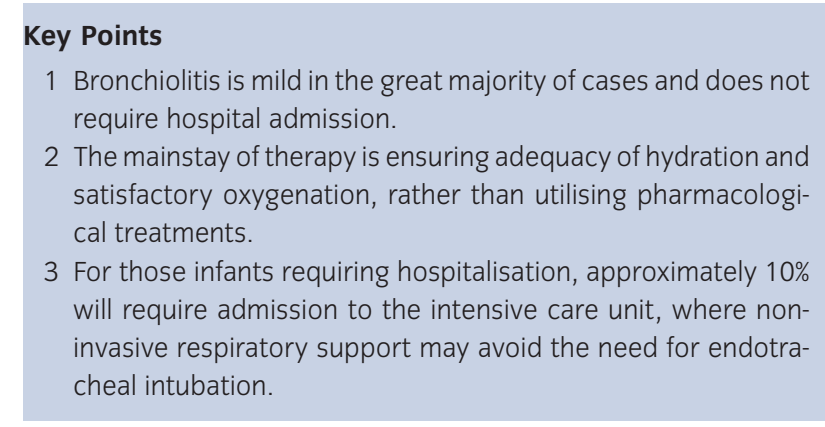

Correspondence: Associate Professor Dominic A Fitzgerald, Department of Respiratory Medicine, The Children's Hospital at Westmead, Locked Bag 4001, Westmead, NSW 2145, Australia. Fax: +61 29845 3396; email: dominif2@chw.edu.au

Accepted for publication 2 September 2009 severe cases that are associated with significant hypoxaemia. ${ }^{3}$ A range of pharmacological treatments have been advocated in the acute settings, but most have not shown consistent benefit. Bronchiolitis that is severe enough to require hospitalisation is associated with an increased subsequent risk of recurrent wheeze in early to middle childhood, but evidence suggests this is because RSV infection is more severe in children with an underlying predisposition to asthma rather than RSV causing asthma. ${ }^{1,3,4}$

\section{Aetiology}

Bronchiolitis is a viral infection. RSV can be detected in about $70 \%$ of cases, but other viruses causing an identical clinical picture include rhinoviruses, parainfluenza viruses, human metapneumoviruses, influenza viruses, enteroviruses, human coronaviruses and human bocaviruses. ${ }^{5,6}$ RSV infection is near universal (95\%) by age 2 years, and $40 \%$ of children infected by 12 months of age develop clinical bronchiolitis. ${ }^{7}$ RSV can be detected in nasopharyngeal aspirates by immunofluorescence, Enzyme-linked immunosorbent assay (ELISA), polymerase chain reaction or viral culture. RSV detection is useful for cohorting patients in hospital to prevent nosocomial infection and, perhaps, to reduce antibiotic use, but is not essential for the diagnosis of bronchiolitis. It has been suggested that dual viral infections and higher RSV viral load are associated with increased severity, but this has not been a consistent finding. ${ }^{6,8-10}$

\section{Epidemiology}

While the majority of children can be managed successfully in the community, $1-2 \%$ will require hospital admission and, of these, $6-12 \%$ will require admission to the intensive care unit. ${ }^{11}$ Maternal antibody is, at best, partially protective, and the 
disease is most severe in very young babies and in babies with underlying risk factors, notably, prematurity, congenital heart disease, particularly cyanotic, and chronic lung disease, and in children with impaired T-cell immunity. ${ }^{3}$

\section{Pathophysiology}

The infecting virus precipitates an inflammatory response in the respiratory epithelium. This gives rise to oedema of the airway wall and an accumulation of mucus and cellular debris within the lumen of the airway. ${ }^{12}$ There is impaired mucociliary clearance with cilial damage and airway occlusion. In an era of molecular medicine, work is beginning to emerge on host defence factors, including the innate immunity of the lung with regard to predisposing factors for more severe bronchiolitis. ${ }^{13}$ However, there are no consistent signals between relative levels of cytokine activity in the blood and lung fluid and the clinical course of bronchiolitis.

Variable bronchiolar obstruction occurs in bronchiolitis, giving way to patchy hyperinflation and areas of atelectasis, evident on the chest radiograph. The infant has overinflated and stiffer lungs, and breathes at a higher lung volume because of a raised functional residual capacity. ${ }^{12,14}$ There is mismatching of ventilation and pulmonary perfusion giving rise to arterial hypoxaemia, and in more severe cases, carbon dioxide retention may be evident.

\section{RSV}

The predominant pathogen in bronchiolitis is the RSV. The RSV is responsible for between $50 \%$ and $80 \%$ of cases of bronchiolitis requiring hospitalisation, but, as stated previously, other viruses are also important causes. ${ }^{1-4,12,15}$ RSV is extremely contagious, with almost all children becoming infected by their second birthday.,16 Transmission requires close contact, with nasal mucosa being exposed to infected secretions, usually either directly through droplet spread or via fomite spread on hands. ${ }^{3,17,18}$ Cross infection in emergency departments and hospital wards remains a considerable challenge. ${ }^{18}$ Reinfection with RSV is common through life, although the first infection tends to be the most severe and is more likely to involve the lower respiratory tract. ${ }^{19,20}$ It is unclear whether simultaneous infections with two or more viruses will lead to a more severe or protracted bronchiolitic illness. ${ }^{19-22}$

\section{Diagnosis}

The diagnosis of bronchiolitis is a clinical one. Most infants present with breathing difficulty in association with a coryzal illness. ${ }^{3,23}$ Neonates may have apnoea, but more typically, babies develop rapid, shallow breathing (often at a rate greater than 60 breaths per min in more severe cases), head bobbing, tracheal tug, chest wall hyperinflation with or without intercostal recession and a characteristic cough. Wheeze is not universal, and the most characteristic auscultatory finding is fine crackles. ${ }^{3,24}$ In those more severe cases managed in the hospital setting, identification of the infecting agent is not only useful for cohorting patients, but may also be of benefit in predicting a higher risk of wheezing in early to middle childhood. ${ }^{25}$

\section{Differential Diagnosis}

In an infant with prolonged symptoms before presentation or atypical features of bronchiolitis, one should consider alternative and/or additional diagnoses, which may include pulmonary aspiration, cardiac failure, bacterial or viral pneumonia, cystic fibrosis, sepsis (with apnoea in very young infants), primary ciliary dyskinesia, tracheomalacia, bronchomalacia, pneumothorax and, finally, in an older child, an inhaled foreign body. ${ }^{3,23}$ The initial investigation in atypical cases of bronchiolitis would be a chest radiograph, where one would look for cardiomegaly with congestive cardiac failure or pneumonia. Moreover, the presence of the usual features of hyperinflation, patchy atelectasis and minor perihilar inflammatory changes should provide support for the diagnosis of viral bronchiolitis and obviate the need for unnecessary therapies such as antibiotics.

The diagnosis of bronchiolitis is relevant for children up to the age of 12 months and, generally, is relevant for the first episode of cough, tachypnoea and wheeze (if present). In later infancy and the toddler years, subsequent episodes of cough, tachypnoea and wheeze triggered by viral infections would fall in to the category of viral-induced wheeze or transient early wheezing, rather than recurrent bronchiolitis. ${ }^{1,3,26}$ Factors that would favour a diagnosis of transient early wheeze would include exposure to environmental tobacco smoke (both antenatally and post-natally] and reduced lung function..$^{1,3,26}$

\section{Assessment of Severity}

A history of preterm delivery, chronic respiratory conditions such as chronic neonatal lung disease or cystic fibrosis, cyanotic congenital heart disease, underlying neurological or neuromuscular conditions, trisomy 21 and immunodeficiency states predicts that the disease will be more severe. ${ }^{3}$ The history of the presenting illness would incorporate days of coryzal symptoms, feeding difficulties, an estimate of reduced urine output as a marker of dehydration and any witnessed apnoea in young infants. ${ }^{3,26}$

The physical examination should begin with a period of observation of the child, who should be undressed down to the nappy. Table 1 lists the basic observations and clinical signs to consider. When making an assessment of severity, one must consider the phase of the illness, the risk factors increasing the likelihood of hospital admission (Table 2) and the findings on physical examination. Bronchiolitis may be considered to be mild, moderate or severe when assessed (Table 3).

\section{Should Any Investigations Be Undertaken When Assessing an Infant with Bronchiolitis?}

For infants with mild viral bronchiolitis, no routine investigations are necessary. ${ }^{3,27}$ For children with moderate to severe bronchiolitis, investigations usually undertaken include:

- Monitoring of patterns of standard clinical parameters of respiratory rate, heart rate and oximetry. This is particularly 
Table 1 Clinical signs to consider in the assessment of severity of bronchiolitis $3,7,23,24,26$

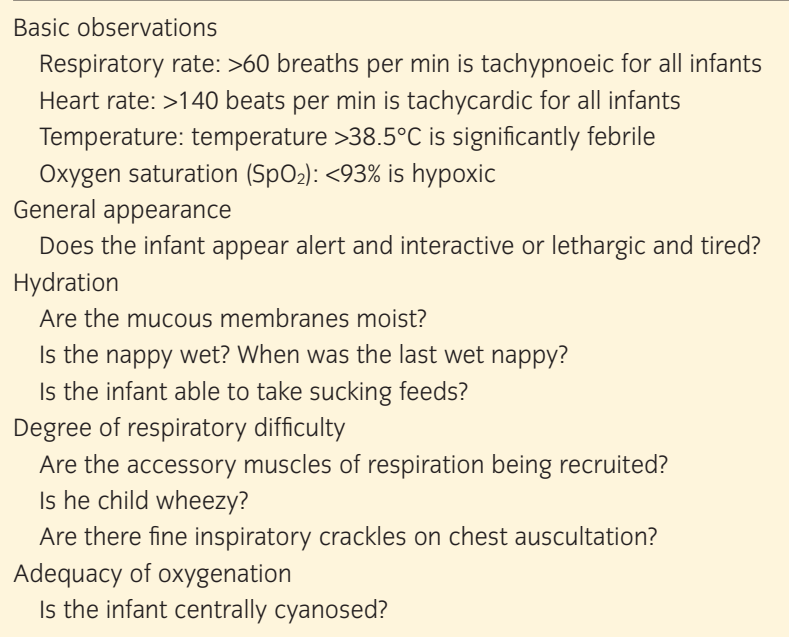

Table 2 Factors likely to prompt hospital admission in infants with bronchiolitis $3,23,24$

Known pre-existing lung or structural cardiac disease

Chronological age $<6$ weeks

Significant preterm delivery (<32 weeks)

History of significant apnoea prior to assessment

Significant dehydration

Moderate or severe breathing difficulty at presentation

Hypoxaemia $\left(\mathrm{SpO}_{2}<93 \%\right)$ or obvious central cyanosis

Re-presentation within $24 \mathrm{~h}$ of initial assessment

Uncertain diagnosis

useful for young infants at risk of apnoea, and routine oximetry has almost certainly contributed to the considerable reduction in mortality from bronchiolitis.

- A chest radiograph: for localised signs of crepitations or wheeze, cardiac murmur and signs of congestive cardiac failure, and to exclude pneumonia.

- A nasopharyngeal aspirate for RSV immunofluorescence and viral culture.

- A full blood count if pneumonia is suspected clinically or from the appearance of the chest radiograph.

- Blood cultures if baby is severely ill or has a fever $>38.5^{\circ} \mathrm{C}$ : septicaemia occurs in $<1 \%$ of normal babies with RSV, but is more likely in babies requiring intensive care unit admission and those with underlying conditions.

- In infants with significant dehydration, serum electrolytes, urea and creatinine.

- Blood gas analysis for an infant requiring an $\mathrm{FiO}_{2}>0.40$ who is tiring, to assess for $\mathrm{pH}$ and carbon dioxide retention. This may be collected as an arterial sample, a free-flowing venous sample or, if unable, a capillary sample.

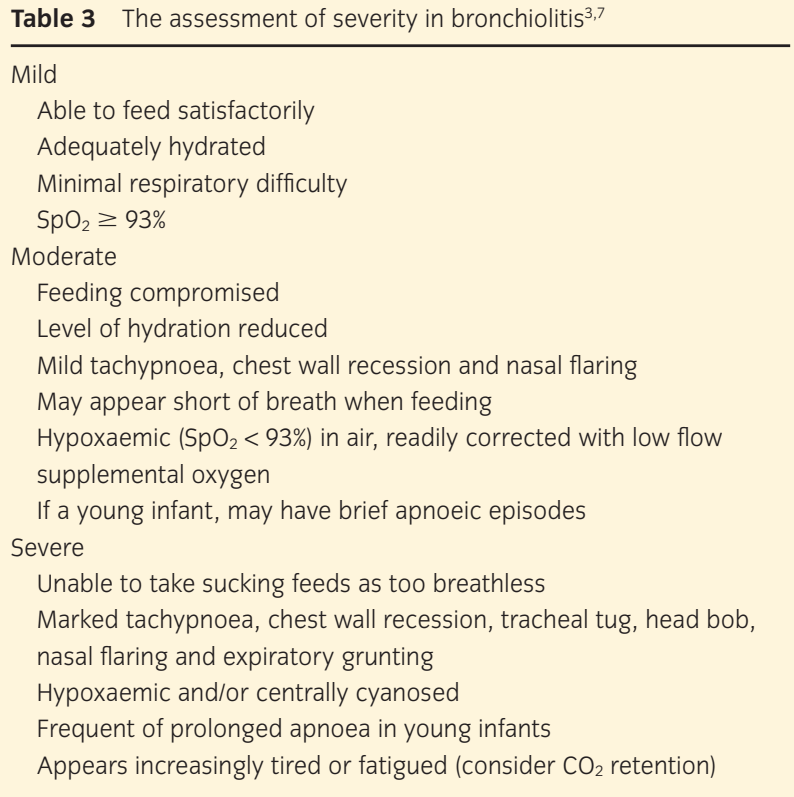

\section{Outpatient Versus Inpatient Management}

The decision to manage the child at home or in hospital is a clinical one, based upon the presenting features and the family circumstances. In cases of mild bronchiolitis, the parents should be reassured, the diagnosis and likely clinical course should be explained, and the child should be offered a review with his/her general practitioner if needed. Infants with moderate to severe bronchiolitis will need admission to hospital for management as they will need supplemental oxygen to overcome hypoxaemia and rehydration with intravenous or possibly nasogastric/ transpyloric fluids in less severe cases. An algorithm for the assessment and treatment of bronchiolitis is provided in Table 4 .

\section{Non-Pharmacological Management}

\section{Hydration}

The combination of nasal congestion for obligate nasal breathers, reduced oral intake, lethargy and malaise, insensible water losses from tachypnoea and increased work of breathing predispose to dehydration in bronchiolitis. ${ }^{3,7}$ The decision to suspend oral feeding because of concerns about pulmonary aspiration is a clinical one, with the introduction of nasogastric or intravenous fluids in the presence of dehydration and increased respiratory work of breathing evident in moderate to severe bronchiolitis. ${ }^{3,7}$ Regular review of hydration status is important.

\section{Nursing issues}

Experienced nursing care is an essential component of the care of infants with bronchiolitis, particularly with regard to the recognition of clinical deterioration, which will require intervention. ${ }^{3}$ The use of normal saline drops into the nose prior to 


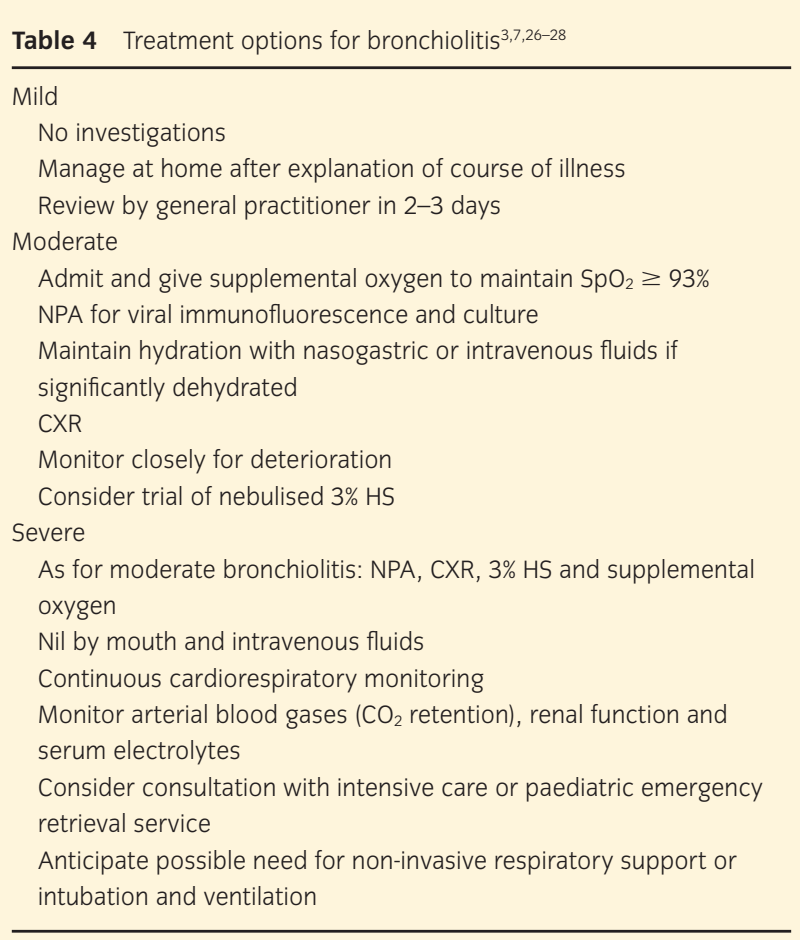

$3 \% \mathrm{HS}, 3 \%$ hypertonic saline; CXR, chest radiograph; NPA, nasopharyngeal aspirate.

feeding is a commonly practiced method to ease nasal congestion, but this has not been subjected to a randomised trial.

\section{Physiotherapy}

A Cochrane review found no evidence to support the use of physiotherapy in the care of infants with bronchiolitis. ${ }^{29}$

\section{Nasal continuous positive airway pressure}

The role of nasal continuous positive airway pressure has increased in recent years. It has been shown to be efficacious in the setting of rising oxygen requirements in an infant who is tiring, where it is useful for reducing the need for endotracheal intubation. ${ }^{28}$ The utility of continuous positive airway pressure is also seen in preterm infants or very young term infants with apnoea.

\section{Pharmacological Treatment at Presentation Oxygen}

Supplemental oxygen delivered via headbox or nasal catheters is the mainstay of therapy for infants with hypoxaemia. However, despite the fact that the oxygen flow rate required to maintain satisfactory oxygenation is used as a proxy for severity, it has been recently demonstrated that it is not possible to reliably estimate the $\mathrm{FiO}_{2}$ reliably from nasal oxygen flow rates in infants with bronchiolitis. ${ }^{30}$ There are no universally accepted thresholds for introducing or weaning supplemental oxygen. In general terms, one would aim to maintain an $\mathrm{SpO}_{2} \geq 93 \%$ in the acute phase and, during recovery, an $\mathrm{SpO}_{2} \geq 90 \%$ in an infant who was feeding adequately and otherwise ready for discharge. ${ }^{3}$

\section{Bronchodilators}

There is no evidence that the bronchodilators salbutamol and ipratropium bromide are associated with a clinically significant benefit when administered to infants with bronchiolitis. ${ }^{31,32}$ Limited by overlap between infants with bronchiolitis and patients with viral-induced recurrent wheeze, a Cochrane review found that bronchodilators did not improve oxygenation or duration of hospitalisation, but did modestly improve clinical scores.

\section{Adrenaline}

An Australian randomised controlled trial ${ }^{33}$ and a Cochrane review ${ }^{34}$ have failed to demonstrate any clinically significant benefit for the use of nebulised adrenaline for infants admitted to hospital with bronchiolitis.

\section{Systemic corticosteroids}

Another Cochrane review determined that systemic corticosteroids for bronchiolitis have no impact on clinical scores, admission rates, length of stay or readmission rates. ${ }^{35}$

\section{Combined nebulised adrenaline and oral dexamethasone}

A recent study suggested a modest benefit of this combined therapy in bronchiolitis, despite the lack of efficacy of the individual treatments. ${ }^{36}$ One would need to treat 11 infants for 1 to benefit. The clinical significance of this treatment is unclear and not recommended for routine therapy.

\section{Nebulised $3 \%$ hypertonic saline}

One of the few therapies, albeit on the basis of only four small trials assessed in a Cochrane Review, shown to improve clinical scores and reduce the length of stay is nebulised 3\% hypertonic saline. ${ }^{37}$ Bronchodilators were given in three of the four studies to minimise the risk of induced bronchospasm from the hypertonic saline.

\section{Antibiotics}

There is no role for the routine use of antibiotics, including macrolides, in bronchiolitis, as the rate of bacteraemia and secondary bacterial infection is extremely low. $3,38,39$

\section{Ribavirin}

This expensive therapy has been used in the intensive care setting but has not been shown to be efficacious in the treatment of bronchiolitis in a Cochrane Review. ${ }^{40}$ Ribavirin has not 
Table 5 Summary of Cochrane Reviews of treatment options in bronchiolitis

\begin{tabular}{lll}
\hline Intervention & Year of Cochrane Review & Conclusion \\
\hline Physiotherapy & $2005^{29}$ & No benefit \\
Systemic corticosteroids & $2007^{35}$ & No benefit \\
Inhaled corticosteroids & $2007^{41}$ & No benefit \\
Bronchodilators & $2006^{31}$ & Probably no significant benefit: not recommended. (case definition problems) \\
Nebulised adrenaline & $2004^{34}$ & No benefit \\
Nebulised 3\% hypertonic saline & $2008^{37}$ & Useful: improved clinical scores \\
Antibiotics & $2007^{38}$ & No benefit \\
Ribavirin & $2004^{40}$ & No benefit \\
\hline
\end{tabular}

been shown to reduce hospitalisation or mortality, and no longterm benefits have been demonstrated with regard to the prevalence of recurrent wheeze or pulmonary function results. There exist concerns about cost, toxicity to staff and, in particular, potential teratogenicity.

\section{Immunoglobulins}

There is no evidence to support the use of intravenous immunoglobulins in the treatment of bronchiolitis. ${ }^{27}$

\section{Clinical Course}

The course for infants requiring hospitalisation varies considerably, from a brief period of observation and improvement over 1-3 days up to prolonged admissions, more commonly in those with predisposing respiratory, cardiac or neuromuscular conditions. During the admission, care is supportive with the provision of adequate hydration and satisfactory oxygenation. Due care is required to minimise the risk of cross infection, with standard hand-washing practices widely used to minimise the risk of fomite spread. ${ }^{3}$ Pharmacological treatment options are limited (Table 5). The criteria for discharge vary, but most infants can be discharged when feeding adequately and when able to maintain adequate oxygenation $\left(\mathrm{SpO}_{2}>90-92 \%\right) .{ }^{3}$ Discharge timing will be influenced by the ability of the parents to attend to the needs of the recovering infant. Ideally, infants admitted to hospital should be reviewed by their general practitioner in the week following discharge. Should the infant develop a persisting cough, tachypnoea or wheeze, review by a paediatrician or respiratory paediatrician should be considered.

\section{Pharmacological Treatment of Post-Bronchiolitis Wheezing}

\section{Montelukast}

Studies have examined the role of the non-steroidal leukotriene receptor antagonist, montelukast, commenced during an episode of bronchiolitis ${ }^{42}$ and for post-bronchiolitic wheeze, ${ }^{43}$ and found the treatment no better than placebo.

\section{Inhaled corticosteroids}

Neither nebulised budesonide (1 mg bd) delivered via a nebuliser during acute bronchiolitis ${ }^{44}$ nor twice daily beclometasone
(200 mcg bd) via a metered dose inhaler and spacer for 3 months following RSV-positive bronchiolitis ${ }^{45}$ was of any clinically significant benefit.

\section{Prophylaxis Against RSV Infection}

There are no vaccines available to prevent RSV infection. The only commercially available pharmacological strategy to prevent RSV infection in Australasia presently is palivizumab, a mouse monoclonal antibody given in five monthly injections that can be used to provide passive immunity to infants at risk of RSV infection. ${ }^{3}$ The therapy reduced the risk of hospitalisation for RSV infection by 50\%, from approximately $10 \%$ to $5 \%$, in randomised controlled trials in children born preterm ${ }^{46}$ and in children with haemodynamically significant congenital heart disease. ${ }^{47}$ The therapy is licensed in Australia, is expensive and is not currently reimbursed by the Pharmaceutical Benefits Scheme. Palivizumab has been criticised as not being costeffective, ${ }^{27,48}$ but, despite this, it is used widely overseas, with many countries having their own guidelines encompassing its use in preterm infants with and without chronic neonatal lung disease, congenital heart disease and immunodeficiencies. ${ }^{3,49}$ The use of palivizumab is arguably best considered on a more limited scale for the most vulnerable infants. ${ }^{50}$

\section{Declaration of Potential Conflict of Interest}

Over the last 5 years, DF has received remuneration from Abbott Australasia, makers of Synagis (palivizumab), for advice on the role of this drug in Australia. In addition, DF has presented at, and/or attended, educational meetings in Australia either partly or wholly sponsored by Merck, Sharpe \& Dohme Australasia, GlaxoSmithKline and AstraZeneca, makers of asthma medications.

\section{References}

1 Martinez FD. Respiratory syncytial virus bronchiolitis and the pathogenesis of childhood asthma. Pediatr. Infect. Dis. J. 2003; 22 S76-82.

2 Wright AL, Taussig LM, Ray CG et al. The Tuscon Children's Respiratory Study. II. Lower respiratory tract illness in the first year of life. Am. J. Epidemiol. 1989; 129: 1232-46.

3 Fitzgerald DA, Kilham HA. Bronchiolitis: assessment and evidence-based management. Med. J. Aust. 2004; 180: 399-404. 
4 Stein RT. Long term airway morbidity following viral LRTI in early infancy: recurrent wheezing or asthma? Paediatr. Respir. Rev. 2009; 10 (Suppl. 1): 29-31.

5 Roe M, O'Donnell DR, Tasker RC. Respiratory viruses in the intensive care unit. Paediatr. Respir. Rev. 2003; 4: 166-71.

6 Marguet C, Lubrano M, Gueudin M et al. In very young infants severity of acute bronchiolitis depends on carried viruses. PLoS One 2009; 4: e4596.

7 AAP Subcommittee on the Diagnosis and Management of Bronchiolitis. Diagnosis and management of bronchiolitis. Pediatrics 2006; 118: 1774-93.

8 Semple MG, Cowell A, Dove W et al. Dual infection of infants by human metapneumovirus and human respiratory syncytial virus is strongly associated with severe bronchiolitis. J. Infect. Dis. 2005; 191 : 382-6.

9 Garcia-Garcia M, Calvo C, Perez-Brena P et al. Prevalence and clinical characteristics of human metapneumovirus infections in hospitalized infants in Spain. Pediatr. Pulmonol. 2006; 41: 863-71.

10 Fodha I, Vabret A, Ghedira L et al. Respiratory syncytial virus infections in hospitalised infants: association between viral load, virus subgroup, and disease severity. J. Med. Virol. 2007; 79: 1951-8.

11 Tsolia MN, Kafetzis D, Danelatou K et al. Epidemiology of respiratory syncytial virus bronchiolitis in hospitalised infants in Greece. Eur. J. Epidemiol. 2003; 18: 55-61.

12 Hall CB. Respiratory syncytial virus and parainfluenza virus. N. Engl. J. Med. 2001; 344: 1917-28.

13 Halfhide C, Smyth RL. Innate immune response and bronchiolitis and preschool recurrent wheeze. Paediatr. Respir. Rev. 2009; 9: 251-62.

14 Krieger I. Mechanics of respiration in bronchiolitis. Pediatrics 1963; 33: 45-50.

15 Papadopouolos NG, Moustaki M, Tsolia M et al. Association of rhinovirus infection with increased disease severity in acute bronchiolitis. Am. J. Respir. Crit. Care Med. 2002; 165: 1285-9.

16 Henderson FW, Collier AM, Clyde WA Jr et al. Respiratory syncytial virus infections, re-infection and immunity. A prospective, longitudinal study in young children. N. Engl. J. Med. 1979; 300: 530-4.

17 Paes BA. Current strategies in the prevention of respiratory syncytial virus disease. Paediatr. Respir. Rev. 2003; 4: 21-7.

18 Isaacs D, Hickson H, O'Callaghan C et al. Handwashing and cohorting in prevention of hospital acquired infections with respiratory syncytial virus. Arch. Dis. Child. 1991; 66: 227-31.

19 Simoes EA. Respiratory syncytial virus infection. Lancet 1999; 354 : 847-52.

20 Shay DK, Holman RC, Newman RD et al. Bronchiolitis-associated hospitalisations among US children, 1980-1996. JAMA. 1999; 282: 1440-6.

21 Marquet C, Lubrano M, Gueudin M et al. In very young infants severity of bronchiolitis depends upon carried viruses. PLOS One 2009; 4 : e4596. Epub 2009 February 25.

22 Aberle JH, Aberle SW, Pracher E, Hutter HP, Kundi M, Popow-Kraupp $T$. Single versus dual viral infections in hospitalized infants: impact on clinical course of disease and gamma-interferon status. Pediatr. Infect. Dis. J. 2005; 24: 605-10.

23 Phelan P, Olinsky A, Robertson C. Clinical Patterns of Acute Respiratory Infections. Oxford: Blackwell Science, 1994; 52-93.

24 Mulholland EK, Olinsky A, Shann FA. Clinical findings and severity of acute bronchiolitis. Lancet 1990; 335: 1259-61.

25 Stensballe LG, Simonsen JB, Thomsen SF et al. The causal direction in the association between respiratory syncytial virus hospitalisation and asthma. J. Allergy Clin. Immunol. 2009; 123: 131-7.

26 Cover RA, Spahn JD. Treating the wheezy infant. Pediatr. Clin. North Am. 2003; 50: 631-54.

27 Lozano JM, Wang E. Bronchiolitis. Clin. Evid. 2002; 8: 291-303.
28 Thia LP, McKenzie SA, Blyth TP, Minasian CC, Kozlowska WJ, Carr SB. Randomised controlled trial of nasal continuous positive airway pressure [CPAP] in bronchiolitis. Arch. Dis. Child. 2008; 93: 45-7.

29 Perrotta C, Ortiz Z, Roque MG. Chest physiotherapy for acute bronchiolitis in paediatric patients between 0 and 24 months old. Cochrane Database Syst. Rev. 2005; CD004873.

30 Sung V, Massie J, Hochmann MA, Carlin JB, Jamsen K, Robertson CF. Estimating inspired oxygen concentration delivered by nasal prongs in children with bronchiolitis. J. Paediatr. Child Health 2008; 44: 14-18.

31 Gadomski AM, Bhasale AL. Bronchodilators for bronchiolitis. Cochrane Database Syst. Rev. 2006; CD001266.

32 King VJ, Viswanathan M, Bordley WC et al. Pharmacologic treatment of bronchiolitis in infants and children: a systematic review. Arch. Pediatr. Adolesc. Med. 2004; 158: 127-37.

33 Wainwright CE, Altamirano L, Cheney $M$ et al. A multicentre, randomized, double-blind controlled trial of nebulized epinephrine in infants with acute bronchiolitis. N. Engl. J. Med. 2003; 349: 27-35.

34 Hartling L, Wiebe N, Russell KF et al. Epinephrine for bronchiolitis. Cochrane Database Syst. Rev. 2004; CD003123.

35 Patel H, Platt R, Lozano JM et al. Glucocorticoids for acute viral bronchiolitis in infants and young children. Cochrane Database Syst. Rev. 2007; CD004878.

36 Plint AC, Johnson DW, Patel $\mathrm{H}$ et al. Epinephrine and dexamethasone in children with bronchiolitis. N. Engl. J. Med. 2009; 360: 2079-89.

37 Zhang L, Mendoza-Sassi RA, Wainwright C et al. Nebulized hypertonic saline solution for acute bronchiolitis in infants. Cochrane Database Syst Rev. 2008; CD006458

38 Spurling GKP, Fonseka K, Doust J, Del Mar C. Antibiotics for bronchiolitis in children. Cochrane Database Syst. Rev. 2007; CD005189.

39 Kneyber MCJ, VanWorsel JBM, Uijtendaal E et al. Azithromycin does not improve disease course in hospitalised infants with respiratory syncytial virus [RSV] lower respiratory tract disease: a randomized equivalence trial. Pediatr. Pulmonol. 2008; 43: 142-9.

40 Ventre K, Randolph A. Ribavirin for respiratory syncytial virus infection of the lower respiratory tract in infants and young children. Cochrane Database Syst. Rev. 2004; CD000181.

41 Blom DJM, Ermers M, Bont L, van Woensel JBM, Van Aalderen WMC. Inhaled corticosteroids during acute bronchiolitis in the prevention of post-bronchiolitic wheezing. Cochrane Database Syst. Rev. 2007; CD004881.

42 Amirav I, Luder AS, Kruger $\mathrm{N}$ et al. A double-blind, placebo-controlled, randomized trial of montelukast for acute bronchiolitis. Pediatrics 2008; 122: e1249-55.

43 Bisgaard H, Florez-Nunez A, Goh A et al. Study of montelukast for the treatment of respiratory symptoms of post-respiratory syncytial virus bronchiolitis in children. Am. J. Respir. Crit. Care Med. 2008; 178: 854-60.

44 Cade A, Brownlee KG, Conway SP et al. Randomised placebo controlled trial of nebulised corticosteroids in acute respiratory syncytial virus bronchiolitis. Arch. Dis. Child. 2000; 82: 126-30.

45 Ermers MJ, Rovers MM, van Woensel JB, Kimpen JL, Bont LJ. The effect of high dose inhaled corticosteroids on wheeze in infants after respiratory syncytial virus infection: randomised double blind placebo controlled study. BMJ. 2009; 338: b897.

46 Anonymous. Palivizumab, a humanized respiratory syncytial virus monoclonal antibody, reduces hospitalization from respiratory syncytial virus in high-risk infants. The impact study group. Pediatrics 1998; 102: 531-7.

47 Feltes TF, Cabalka AK, Meissner HC et al. Palivizumab prophylaxis reduces hospitalization due to respiratory syncytial virus in young children with hemodynamically significant congenital heart disease. J. Pediatr. 2003; 143: 532-40. 
48 Embleton ND, Harkensee C, McKean MC. Palivizumab for preterm infants. Is it worth it? Arch. Dis. Child. Fetal Neonatal Ed. 2005; 90 : F286-9.

49 Resch B, Manzoni P, Lanari M. Severe respiratory syncytial virus [RSV] infection in infants with severe neuromuscular diseases and immunodeficiency syndromes. Paediatr. Respir. Rev. 2009; 10: 148-53.

50 Fitzgerald DA. Preventing bronchiolitis in vulnerable infants: the role of palivizumab. Paediatr. Respir. Rev. 2009; 10: 143-7.

\section{Appendix I}

\section{Multiple choice questions}

1. Infants at greater risk for hospitalisation with RSV +ve bronchiolitis:

a. Secundum ASD

b. Tetralogy of Fallot

c. Preterm delivery at $<28$ weeks gestation

d. Transient tachypnoea of the newborn

e. Hereditary spherocytosis

Infants with extreme preterm delivery and those with haemodynamically significant cardiac disease are at greater risk of hospitalisation for RSV +ve bronchiolitis.
2. The following pharmacological treatments are of benefit in infants hospitalised with bronchiolitis:

a. Inhaled corticosteroids

b. Nebulised 3\% hypertonic saline

$[\mathrm{T}]$

c. Nebulised adrenaline

d. Ribavirin

e. Montelukast

Only nebulised 3\% hypertonic saline has been shown to be of benefit in bronchiolitis.

3. An infant with mild bronchiolitis will display the following signs:

a. Mild tachypnoea

b. Significant hypoxaemia $(\mathrm{SpO} 2<90 \%) \quad[\mathrm{F}]$

c. Dehydration

d. Carbon dioxide retention on a blood gas

e. Apnoea

Mild bronchiolitis will be associated with mild tachypnoea, although gas exchange, feeding and hydration will not be significantly compromised. 